\title{
SOS Móvel: sistema para auxiliar pessoas na solicitação de socorro
}

\author{
Suellem Stephanne Fernandes Queiroz ${ }^{1}$ \\ Cicilia Raquel Maia Leite ${ }^{1}$ \\ Pedro Fernandes Ribeiro Neto ${ }^{1}$ \\ Davi Alves Magalhães ${ }^{1}$ \\ José Erico Gomes da Silva
}

\begin{abstract}
Resumo: Devido aos índices elevados de acidentes, incidentes e ocorrências, qualquer um está vulnerável e pode necessitar de informações sobre centros de saúde mais próximos para o socorro. $\mathrm{Na}$ busca de reduzir o alto índice de ocorrências fatais em acidentes e incidentes quaisquer, medidas tecnológicas passaram a ser empregadas para contatar rapidamente o socorro. O SOS móvel é um sistema para auxiliar pessoas na solicitação de socorro. O sistema faz reconhecimento de atividades, utiliza sensores móveis com sensibilidade ao contexto e um agente inteligente para detecção de situações de risco e disparo de solicitações de socorro automáticas. O sistema é composto por uma parte web e uma móvel. O aplicativo móvel é utilizado ativamente pelo usuário, enquanto que a interface web é utilizada pelos familiares ou gestores da saúde que podem monitorar o usuário e visualizar sua localização e alertas. Os experimentos com o SOS Móvel foram realizados em um ambiente de simulações e permitiram concluir que esse apresentou desempenho satisfatório ao detectar riscos e fazer o envio de solicitações de socorro automaticamente.
\end{abstract}

Palavras-chave: Detecção de risco. Solicitação de socorro. Sensores móveis. Sensibilidade ao contexto. M-Health.

\begin{abstract}
Due to the high rates of accidents, incidents and occurrences, anyone is vulnerable and may need information on health centers closer to the rescue. In seeking to reduce the high rate of fatalities in accidents and any incidents, technological measures started to be used to quickly contact help. The Mobile SOS is a system to help people in distress request. The system recognition activities, using mobile sensors with sensitivity to context and an intelligent agent for the detection of risk situations and trigger automatic emergency requests. The system comprises a web portion and a mobile. The mobile application is actively used by the user, while the web interface is used by family or health managers can monitor the user and view its location and alerts. Experiments with Mobile SOS were performed in a simulated environment and concluded that it showed satisfactory performance to identify risks and make sending aid requests automatically.
\end{abstract}

Keywords: Risk of detection. Request for help. Mobile sensors. Context-aware. M-Health.

\section{Introdução}

Em escala mundial, acidentes e incidentes são causas de dizimações diárias em milhares de pessoas ou são os responsáveis por causar mutilações e sequelas que aprisionam os indivíduos às suas enfermidades.

\footnotetext{
${ }^{1}$ Programa de Pós-Graduação em Ciência da Computação (PPGCC), Uern/Ufersa, Campus Central - BR 226 - Mossoró (RN) - Brasil

\{suellem.sfq@gmail.com, ciciliamaia@gmail.com, pedro.fernandes2503@gmail.com, davialvesmagalhaes@gmail.com\}

${ }^{2}$ Departamento de Informática, Uern, Campus Central - Rua Almino Afonso, 478 - Centro - Mossoró (RN) - Brasil \{jerick.gs@gmail.com\}
}

http://dx.doi.org/10.5335/rbca.v8i3.5920 
Conforme dados coletados pela [1], sobre a distribuição de atendimentos devido a violências e acidentes de urgências e emergências, constatou-se que o tipo de ocorrência mais frequente de acidente no Brasil diz respeito a quedas, com $30,9 \%$ da porcentagem, seguido por acidentes de transporte, com $26,2 \%, 8,4 \%$ de agres sões, $1,9 \%$ de queimaduras, $0,9 \%$ de lesões e $0,1 \%$ intervenções. Demais acidentes e incidentes, como afogamento, ferimento por arma de fogo, choques e etc., contabilizaram 31,6\% das ocorrências totais.

Os acidentes intencionais ou não intencionais que resultam em fatalidades podem ocorrer devido a um conjunto de circunstâncias que são decisivas para a sobrevivência de um indivíduo. Um dos principais fatores de risco é a espera pelo socorro. O tempo gasto desde contatar uma Serviço de Atendimento Móvel de Urgência (Samu) até a prestação de socorro a uma pessoa pode ser um fator decisivo entre a vida e a morte. Para pessoas que sofreram parada cardíaca, por exemplo, cada minuto de atraso para resgate reduz a taxa de sobrevivência de $7 \%$ a $10 \%$. Se o procedimento de ressuscitação cardiopulmonar for realizado dentro de 5 minutos, a porcentagem de sobrevivência sobe para $30 \%$, caso contrário diminui para $7 \%$ com redução gradual entre $3 \%$ e $4 \%$ por minuto [2]. As ações de socorro durante os minutos iniciais de atendimento a uma emergência são fatores determinantes em relação à sobrevivência de uma vítima.

Diante do contexto abordado, o objetivo deste trabalho é desenvolver um sistema para auxiliar no pedido de socorro e detecção automática de situações de risco. O sistema funcionará de modo similar aos botões de pânico padrões, porém com a agregação de reconhecimento de atividades, sensores móveis com sensibilidade ao contexto e agentes para disparo de solicitações de socorro e reconhecimento de possíveis acidentes. O sistema é desenvolvido para utilização em Sistema Operacional (SO) Android e tem também uma interface de monitoramento e recebimento de alertas web.

\section{Fundamentação teórica}

Esta seção é destinada à apresentação da teoria na qual o trabalho está embasado, abordando conceitos teóricos necessários ao desenvolvimento desse, de modo que constitua suporte para estudos e coleta de informações qualitativas.

\subsection{Sensores móveis}

Os sensores, em termos físicos, são componentes de hardware conectados aos dispositivos de forma que fornecem dados do mundo real para as aplicações, detectando sinais ou condições físicas. A maioria são elétricos ou eletrônicos e são amplamente utilizados em diversos dispositivos de uso pessoal. Os sensores podem prover a percepção de contextos específicos, como a orientação da tela de um dispositivo, a temperatura local, a luminosidade, o som local, a aceleração, dentre outros [3]. Os sensores nos Smartphones seguem um quadro de coordenadas para detecção e extração de algumas de suas características físicas. Um quadro de coordenadas é um sistema no qual a orientação dos três eixos é definida em referência a um objeto [8].

Os movimentos captados pelos sensores de um Smartphone, com relação à orientação e à movimentação do dispositivo são classificados em três propriedades: alfa, beta e gama, que correspondem à rotação do dispositivo em graus em torno dos eixos $\mathrm{z}, \mathrm{x}$ e y, respectivamente. A propriedade beta tem um intervalo de $-180^{\circ}$ a $+180^{\circ}$, já o gama, entre $-90^{\circ}$ a $+90^{\circ}$. Um dispositivo em repouso horizontalmente deve reportar beta e gama com valores zero. A inclinação total da tela do dispositivo para a direita aumenta a gama positivamente a $90^{\circ}$, e o oposto, diminui para $-90^{\circ}$. De igual modo, inclinando o dispositivo para a frente e elevando uma das suas extremidades em direção ao usuário, eleva-se o beta no sentido de $90^{\circ}$. A inclinação para baixo o diminui no sentido de $-90^{\circ}$. O ângulo alfa é de $0^{\circ}$ quando a parte superior do dispositivo é apontada ao polo norte do planeta e é acrescida à medida que esse é direcionado para a esquerda [8].

Existem dois tipos de quadro de coordenadas quando são utilizados eventos de orientação e de movimento: o quadro de coordenadas geográficas e o quadro de coordenadas do dispositivo. A maior parte dos Smartphones tem, no mínimo, dois sensores considerados "base", que são os chamados sensores de movimento, compreendendo os sensores: acelerômetro, que detecta a variação de movimento ou aceleração nos eixos $\mathrm{x}, \mathrm{y}, \mathrm{z}$; e o giroscópio, que mede e obtém a orientação do aparelho [4].

Um sensor de aceleração mede a aceleração aplicada ao dispositivo, incluindo a força da gravidade. $\mathrm{O}$ acelerômetro é um componente eletrônico que mede as forças de aceleração que são exercidas em um 
determinado objeto. O princípio de funcionamento dos acelerômetros se faz a partir da movimentação do segmento, ou do local onde o sensor foi fixado, que com sua inércia, em relação a uma base fixa no seu interior, é detectada e transformada em um sinal elétrico. Quando um objeto encontra-se em repouso, os sinais do acelerômetro indicam a sua aceleração estática, que é medida por meio da projeção da aceleração da gravidade sobre os eixos do acelerômetro para determinar o ângulo de inclinação do dado objeto [8][4]. Um acelerômetro de um Tablet ou Smartphone é capaz de medir acelerações no intervalo $2 \mathrm{G}$ (G corresponde a aceleração da gravidade) positivo ou negativo, em relação a um referencial inercial [3].

Assim como os acelerômetros medem variações do movimento translacional, os giroscópios medem variáveis do movimento rotacional ou orientação dos acelerômetros. O giroscópio utiliza a gravidade da Terra para determinar orientações e mede a variação da rotação em rad/s em torno dos eixos x, y e z [5]. A principal diferença entre o acelerômetro e o giroscópio diz respeito ao fato de um poder medir a rotação, enquanto o outro, a aceleração. Ao acelerar um dispositivo em uma determinada direção, o acelerômetro é incapaz de distinguir entre essa aceleração e a fornecida por meio da força gravitacional da Terra. O giroscópio mantém o seu nível de eficácia por ser capaz de medir a velocidade de rotação em torno de um determinado eixo [4][8].

\subsection{Sensibilidade ao contexto}

A sensibilidade ao contexto, do inglês Context-Aware, descreve um paradigma no qual o contexto de um usuário é relevante para definição do seu perfil atual. Em ambientes nos quais há sensibilidade ao contexto, as informações fornecidas pelo usuário são obtidas dinamicamente, a partir da interação com os dispositivos computacionais, levando em consideração o ambiente no qual estão inseridos [6].

A Computação Sensível ao Contexto pode ser definida como um paradigma computacional que utiliza informações contextuais obtidas por meios diversos, de modo a agregar valor aos seus serviços, possibilitando a adaptação, a expansão, a restrição ou a alteração de suas funcionalidades conforme as mudanças percebidas nos contextos observados. Todos os tipos de atividades, incluindo a comunicação entre humanos, são rodeadas e influenciadas por um ou mais contextos [9].

Para que seja possível utilizar contextos em aplicações, é preciso haver mecanismos que permitam perceber o contexto atual e o descrevam para a aplicação. A obtenção da localização do usuário e sua movimentação ao longo do espaço são informações contextuais de grande relevância para a sensibilidade ao contexto. A captação dos registros dos contextos de localização vindos dos dispositivos faz com que seja perceptível a proximidade entre as pessoas e os aparelhos tecnológicos.

Efetivamente, a maioria das informações disponíveis em um dado momento da interação pode ser identificada como contextual, dentre as quais, pode-se destacar algumas: as diversas tarefas exigidas pelos usuários; a grande quantidade de dispositivos que se combinam para a criação de sistemas móveis com infraestrutura de serviços associada; a disponibilidade de recursos, como por exemplo, a condição da bateria, o tamanho de tela do dispositivo, dentre outros; a situação física, a exemplo o nível de ruído, a temperatura, o nível de luminosidade; a informação espacial, como sua localização, velocidade, orientação, etc.; e sua informação temporal, como por exemplo a hora do dia, data e outros [6].

Em Smartphones, Tablets e dispositivos pessoais móveis, tornou-se comum a agregação de tecnologias, como Bluetooth, Near Field Communication (NFC) e GPS. Essa última, por exemplo, possibilita localizar o dispositivo e obter dados de sua localização em diversos formatos. Sensores também são meios que podem prover a percepção de contextos específicos, como a orientação e posicionamento do dispositivo, temperatura local, luminosidade, aceleração, etc. [7].

\subsection{M-Health}

A utilização do potencial oferecido pelas atuais tecnologias de telecomunicação na prestação de cuidados médicos tem trazido muitos benefícios para a população que necessita de assistência médica, tornando-se um elo entre aqueles que não têm condições de acessar centros médicos e profissionais da área. O termo M-Health, do acrônimo Mobile Health, tem sido utilizado, atualmente, proveniente de uma das áreas da telemedicina. MHealth é o conceito de apoio a práticas médicas e de saúde pública por meio de dispositivos móveis e sem fio, a fim de facilitar e melhorar os resultados de serviços prestados na área médica [10]. 
Um dos principais objetivos do M-Health é reduzir o custo dos cuidados médicos, maximizando a eficiência no sistema de saúde e promovendo a prevenção [11]. Além disso, o M-Health também tem o benefício do acompanhamento diário obrigatório por parte de alguns pacientes com determinadas doenças que exigem assistência frequente, o que traz alívio àqueles que necessitam de cadeira de rodas para se locomover ou pacientes acamados, impossibilitados de ir a centros médicos para a realização de diagnósticos e testes.

Com o advento de telefones com tecnologia avançada e inteligente (Smartphones) nos últimos anos, o MHealth tem se tornado mais abrangente devido à utilização de um dispositivo móvel para a execução de vários serviços de maneira potencializada. De certa forma, o M-Health transforma o tradicional modo de cuidado de saúde, permitindo, assim, que esses continuem sendo executados, porém, de forma otimizada e ágil, ou seja, a qualquer momento e em qualquer localidade. É possível, por meio do M-Health, promover cuidados preventivos, gerenciar o cuidado de doenças crônicas e demais enfermidades, e, principalmente, obter resultados para melhorar o bem-estar pessoal da população em geral [11].

\section{Sistema para auxiliar no pedido de socorro e detecção automática de situações de risco}

Esta seção é destinada à apresentação do SOS móvel, objeto de desenvolvimento deste trabalho.

\subsection{Visão geral}

O SOS móvel é um sistema de detecção e solicitação de socorro formado por duas partes que interagem entre si: um aplicativo para Smartphones e dispositivos móveis com SO Android e uma interface de gerenciamento na internet. $\mathrm{O}$ aplicativo é o componente que será utilizado ativamente pelo usuário, enquanto a interface web permitirá que familiares e/ou gestores da saúde possam monitorar e acompanhar remotamente o usuário, como também visualizar seu histórico de alertas e localização.

A aplicação móvel leva em consideração dois níveis de solicitação de socorro, são eles o manual e o automático. O primeiro, o manual, possibilita ao usuário escolher como realizar seu pedido de socorro, podendo optar entre avisar familiares ou enviar um alerta de emergência diretamente aos serviços de atendimento de urgência. Nesse modo, o usuário precisa interagir diretamente com o dispositivo móvel para realizar a solicitação.

No segundo nível, o automático, o SOS móvel permanece constantemente detectando o que o usuário está fazendo e define situações anormais para cada atividade identificada, assumindo que esse esteja em perigo. Para cada atividade detectada, há um conjunto de condições para que essa ação seja reconhecida como atípica. Ao constatar a anormalidade, se o usuário não confirmar uma detecção de um "alarme falso", automaticamente é disparado um alerta aos cuidadores e familiares contendo sua geolocalização, horário e data. Nesse nível, usuário não necessita interagir com o Smartphone diretamente.

O monitoramento do usuário se dá pela interface web em que é possível ter informações sensíveis ao contexto da localidade do usuário em tempo real, seu histórico de solicitações de socorro e também receber novos alertas. Para utilizar o SOS móvel web, é preciso que o familiar ou responsável use o número de telefone do usuário como seu login e seu próprio telefone como a senha. Dessa forma, apenas os números salvos no cadastro do usuário podem utilizar o sistema.

\subsection{Etapas}

O desenvolvimento do SOS móvel foi realizado em cinco etapas, detalhadas nas subseções seguintes. São elas a configuração do ambiente, a aquisição de dados, o pré-processamento, o processamento e o pósprocessamento. A Figura 1 apresenta a arquitetura do SOS móvel, bem como sua visão geral e etapas seguidas, desde a coleta de dados até a obtenção dos resultados. 


\subsection{Configuração do ambiente}

A configuração do SOS móvel inicia-se pela interface móvel, em que o usuário é submetido à realização de um cadastro, caso ainda não possua. $\mathrm{O}$ cadastro é uma função obrigatória, pois nele, é possível o usuário informar doenças portadas e contatos familiares de emergência. A personalização das mensagens de socorro também faz parte da configuração do ambiente, pois essas são salvas e enviadas ao servidor como alertas com sensibilidade ao contexto. Por meio da interface de gerenciamento web, é possível receber os alertas enviados pela interface móvel e, assim, localizar o usuário. A conexão via web se dá por meio do login associado ao número de telefone dos contatos do usuário cadastrado. No SOS Móvel, foi utilizado o SQLite para criar um banco de dados da aplicação, usando o modelo de dados relacional. O MySQL foi o Sistema de Gerenciamento de Banco de Dados (SGBD) utilizado para gerir as informações recebidas da aplicação SOS Móvel pelo servidor. A aplicação móvel tem um banco de dados interno, no qual é utilizado o sqLite para modelagem; possui, ainda, um outro banco de dados externo que faz conexão com o servidor via JSP.

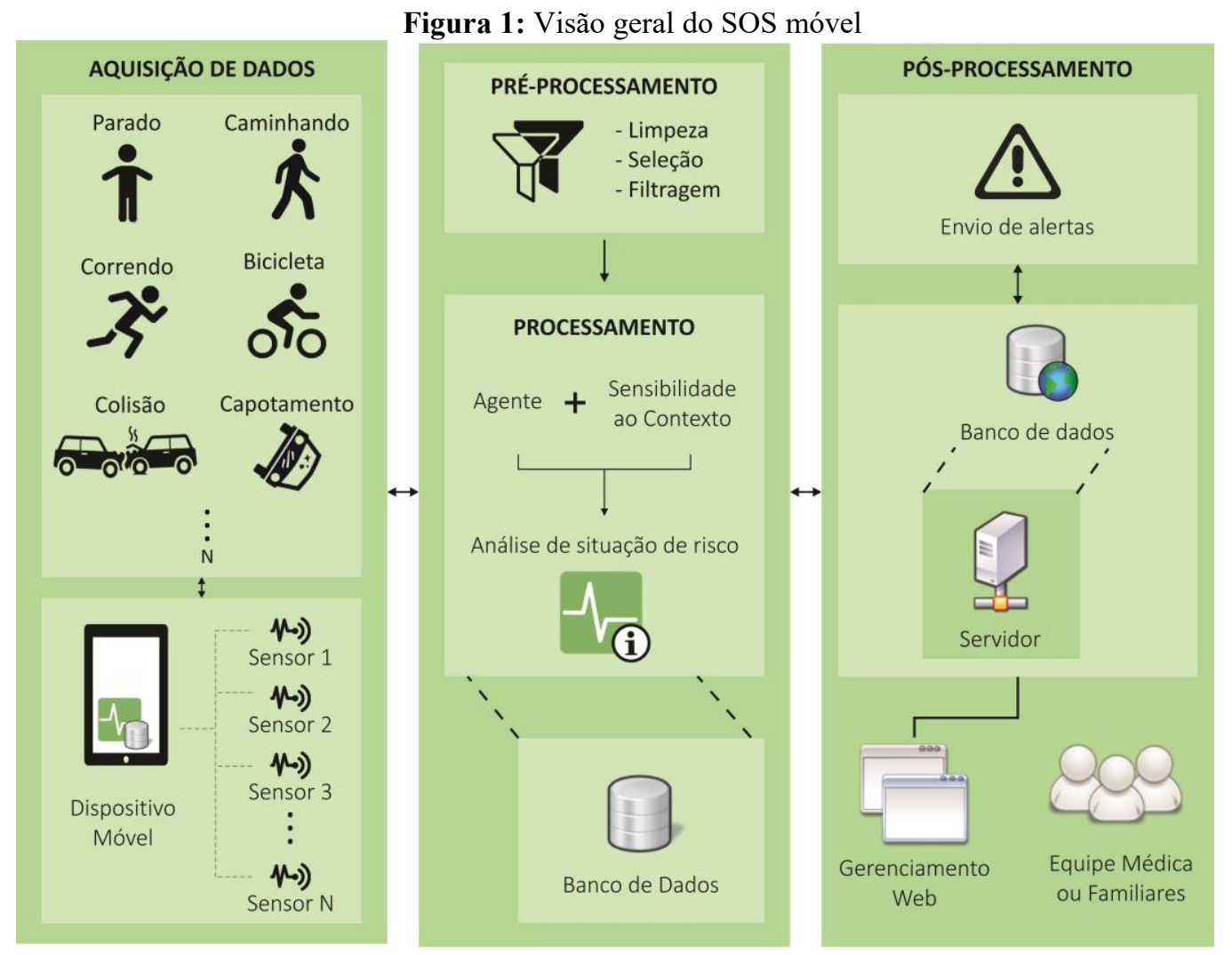

\subsection{Aquisição de dados}

A aquisição de dados foi realizada por meio da utilização do acelerômetro, giroscópio e magnetômetro presentes no próprio Smartphone, em conjunto com a API activy Recognition para executar constantemente a detecção do que o usuário está fazendo. Os dados coletados foram, inicialmente, dos sensores de aceleração (normal e linear), de rotação e intensidade de campo magnético, de localização, além das seis atividades reconhecidas pela API usada (parado, caminhando, correndo, bicicleta, colisão frontal e capotamento).

\subsection{Pré-processamento}

Essa etapa foi responsável pela realização da filtragem e da seleção dos principais sensores a serem utilizados para este trabalho, que foram o sensor de aceleração linear, o giroscópio, o magnetômetro e o GPS. Foi constatado que, ao utilizar apenas o acelerômetro, o eixo z permanecia com seu valor constante de $+9,81$ 
mesmo em seu estado de repouso total. Esse valor corresponde à aceleração do dispositivo, em $\mathrm{m} / \mathrm{s}^{2}$, considerando a força gravitacional da terra.

Dessa forma, foi utilizado o sensor de aceleração linear, pois esse considera os valores do eixo z já com os descontos gravitacionais, justificando o uso do sensor. Entretanto, foi, também, utilizado indiretamente o acelerômetro, em razão de que a API utiliza o acelerômetro em seu estado interno para o cálculo e o reconhecimento das atividades, o que resulta no uso total de quatro sensores base para o desenvolvimento deste trabalho. São eles o giroscópio, o acelerômetro, o magnetômetro e a aceleração linear.

Foi, igualmente, realizada a restrição das atividades reconhecidas pela API, reduzindo-as a seis. São elas: parado, caminhando, correndo, bicicleta, colisão frontal e capotamento. Nessa etapa, também foram definidas quais seriam as situações de emergência para cada atividade citada. Para as atividades parado, caminhando, correndo e andando de bicicleta, as possíveis situações de emergência estabelecidas para detecção foram queda e desmaio. Para a atividade de dirigir o carro, é possível identificar uma batida (colisão frontal) e capotamento.

\subsection{Processamento e pós-processamento}

Nessa etapa, encontra-se a parte principal do desenvolvimento do trabalho, abordando como foi desenvolvido. O SOS Móvel possui um agente que permanece constantemente "observando" a atividade que o usuário está fazendo, por meio da API Activity Recognition. Basicamente, a tarefa do agente se divide em três partes. A primeira delas é receber a dedução da atividade por meio da API e o armazenamento de seu resultado. Posteriormente, recebe os dados dos sensores de aceleração linear, giroscópio e magnetômetro para calcular a rotação do celular. Na terceira parte, o agente permanece verificando constantemente a aceleração linear e se detectar variações maiores que $5.0 \mathrm{~m} / \mathrm{s}^{2}$ nos três eixos, esse analisa os dados das outras duas partes descritas para assim determinar se houve um acidente ou não.

O agente é executado na implementação sempre que algum sensor sofre alguma mudança e é invocado pelo próprio Android na aplicação como forma de avisar que tem novos dados identificados. Dependendo da capacidade do dispositivo e da taxa de atualização estabelecida, esse método é chamado, aproximadamente, de 200 a 500 vezes por segundo para cada sensor separadamente. O armazenamento dos dados é de acordo com o tipo de cada sensor em uso. Nesse caso, três variáveis, correspondentes a acelerômetro, magnetômetro e aceleração linear, respectivamente. Se o agente já possuir esses dados, então é obtida a matriz de rotação por meio de acelerômetro, magnetômetro e dois vetores. O método nativo da API Android, o getRotationMatrix, gera a matriz de rotação responsável por mapear as coordenadas do dispositivo em coordenadas geográficas.

Durante a execução da aplicação, é obtida a matriz de rotação da posição do celular nos eixos z, x, e y e adicionada essa posição a uma variável chamada janelaGiroscopio, para representação de um ponto de três eixos. Esse procedimento foi necessário apenas ao giroscópio, devido à necessidade de o agente analisar o fluxo observando o janelamento de dados, como um conjunto de valores de uma fila de duzentas posições. A análise de apenas um valor pontual para o caso do giroscópio não é relevante, visto que o que se busca é saber se houve rotação. E, para identificar a rotação, é preciso comparar o valor do dado atual do sensor com os outros valores anteriores dentro de uma janela de tempo.

Dentro da variável janelaGiroscopio, há um vetor dinâmico (arraylist) chamado Ponto3D. Após adicionada a posição do dispositivo na janela de dados janelaGiroscopio, é verificado se o tamanho do janelamento é superior ao limite estabelecido (duzentos), para que, se for, seja removido o valor excedente de posição mais antiga, para recebimento de um novo no final da fila. Dentro do janelamento é analisado apenas o eixo y. É percorrido todo o vetor da janela em busca de mudança de sinal. Primeiramente, é obtido o valor mais recente e verificado se esse é menor do que zero. Se for, ou seja, se for negativo, então é percorrido todo o vetor do eixo y em busca de algum número que seja positivo, pois isso indicaria uma mudança de sinal. Inversamente, se o primeiro valor não for negativo, também é percorrido o vetor para realizar a mesma ação em busca de um número oposto. Como resposta é retornado true, se achar, ou false, se não achar, indicando que não houve rotação.

Ao realizar o cadastro, algumas informações do usuário são salvas no BD da aplicação e logo em seguida todas são sincronizadas para o BD do servidor. No gerenciamento web, é possível visualizar todas as ocorrências de emergência presentes no banco de dados para o usuário logado, bem como receber alertas de novas solicitações e suas respectivas informações emergenciais, como localização, SMS com prévia do motivo do pedido, etc.

Revista Brasileira de Computação Aplicada (ISSN 2176-6649), Passo Fundo, v. 8, n. 3, p. 34-50, out. 201639 


\subsection{Funcionalidades do sistema}

O cadastro do usuário é uma função obrigatória para utilização do SOS móvel, pois é nesse que são informados dados básicos do usuário, como nome, telefone, doenças portadas e o número de três contatos emergenciais. As informações são salvas no banco de dados da aplicação e, posteriormente, sincronizadas para o banco de dados do servidor. Os cadastros e demais informações são mantidos sincronizados automaticamente.

O usuário realiza login apenas por meio do número do celular informado. Esse faz parte da tabela Usuários, na qual tal número é a chave primária e serve como identificador único do usuário. Uma vez efetuado o cadastro, a aplicação não exige mais a realização desse, permanecendo logado àquele número, a menos que seja apagada a aplicação ou seu cache. Essa funcionalidade estará presente apenas no aplicativo utilizado pelo usuário.

No cadastro, o usuário informa três números emergenciais para envio de mensagens rápidas, caso solicite ajuda manualmente. $\mathrm{Na}$ tela inicial, são exibidos três botões principais de texto, em que estão contidas as mensagens predefinidas pelo usuário. Ao pressionar um dos três botões emergenciais, se confirmada, a informação descrita nele é enviada para os três números emergenciais do cadastro do usuário. Essa funcionalidade tem o intuito informar previamente a familiares ou cuidadores o que o usuário está necessitando ou sentindo. A Figura 2 exibe as telas para as funcionalidades descritas.

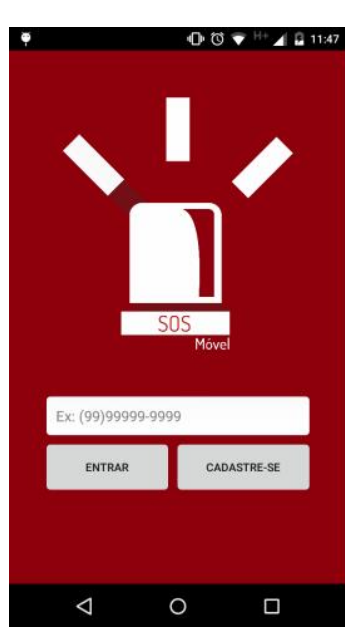

Figura 2: Telas principais do SOS móvel

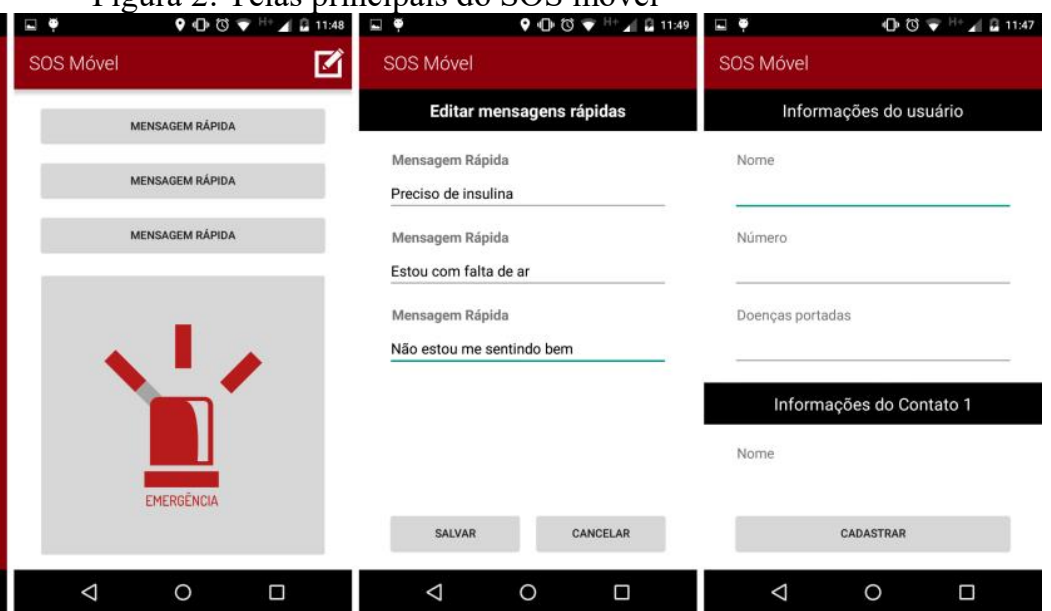

O monitoramento do usuário se dá pela interface web (Figura 3) em que é possível ter informações sensíveis ao contexto da localidade do usuário em tempo real, seu histórico de solicitações de socorro e, também, receber novos alertas. Para utilizar o SOS Móvel web, é preciso que o familiar ou responsável use o número de telefone do usuário como seu login e seu próprio telefone como a senha. Dessa forma, apenas os números salvos no cadastro do usuário podem utilizar o sistema.

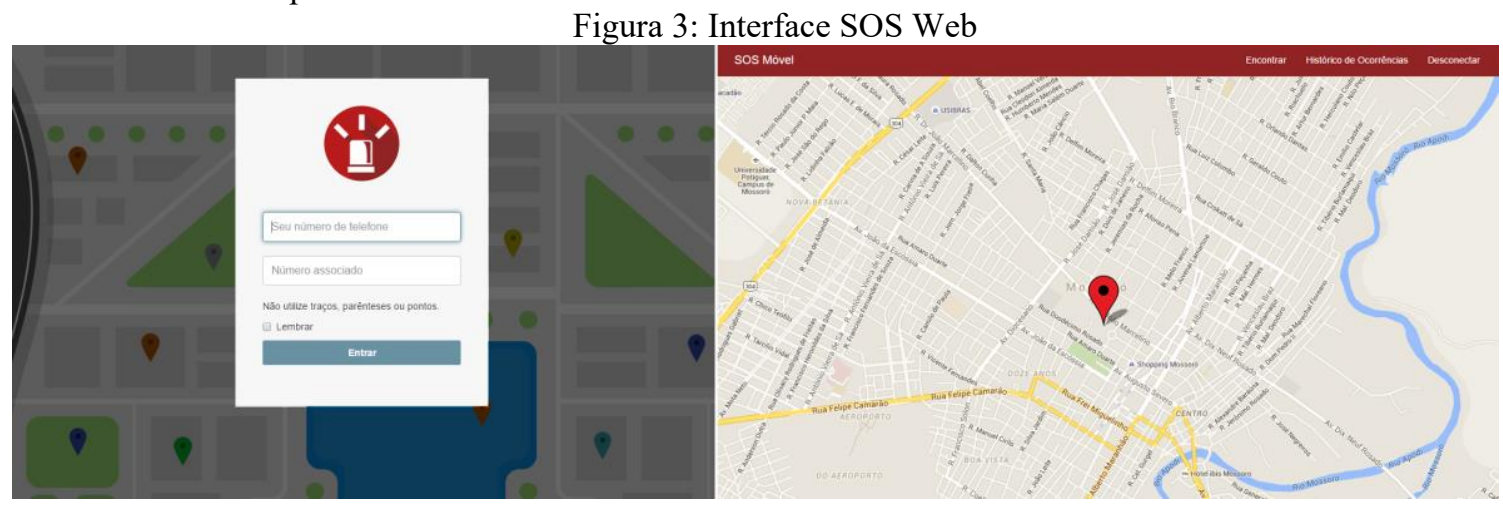

Ao iniciar a aplicação, após a realização do cadastro e do login, inicia-se a identificação da atividade e a aplicação permanece executando em modo de serviço. Mesmo que o usuário feche a aplicação, o serviço continuará ativo, realizando a detecção de situações de risco.

A API Activity Recognition permite detectar qual atividade o usuário está envolvido sem o incômodo de obter dados brutos de sensores individuais e, em seguida, ter de executar uma análise complexa para chegar a 
uma conclusão. A API retorna a atividade detectada em conjunto com a confiança de seus resultados. Como resultado, tem-se uma lista de atividades que um usuário pode estar executando em um determinado momento, as quais são classificadas segundo probabilidade em primeiro lugar. A confiança está associada a cada atividade, que indica a probabilidade de qual atividade está sendo realizada.

A solicitação de socorro pode ser realizada manualmente e de forma automática. A primeira delas, a manual, é realizada ao pressionar o botão de emergência que se encontra na tela principal. Foi acrescentado uma confirmação de envio para diminuir possíveis erros. A solicitação é enviada para o servidor e exibida como alerta na interface web, junto com localização, horário e data.

$\mathrm{Na}$ forma automática, a aplicação móvel permanece em execução e, ao serem diagnosticados valores excedentes ao limite de uma atividade para os eixos do acelerômetro, também é enviado para o servidor o alerta para ser exibido na interface web com os dados adicionais. Desse modo, não é necessária a interação do usuário para realizar a solicitação. Também foi adicionado um alerta com duração de 1 minuto ao modo automático, para o caso de anulação de solicitação se for detectada uma situação de risco equivocada (Figura 4).

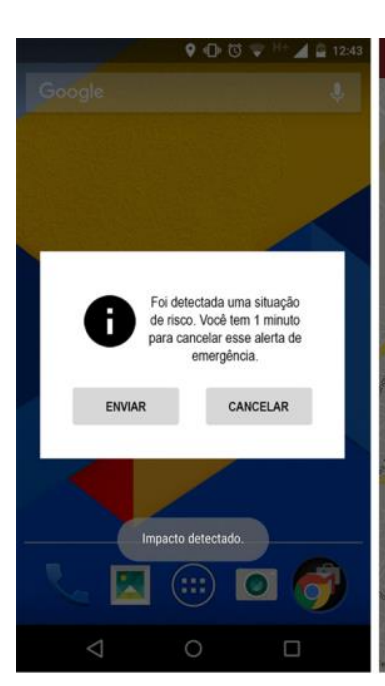

Figura 4: Notificação de socorro

\section{Estudo de caso: aplicação do SOS móvel em ambiente de testes}

Esta seção é destinada à apresentação do estudo de caso. O estudo de caso expõe a pesquisa, a análise e a interpretação dos dados coletados, além dos resultados quantitativos obtidos.

\subsection{Descrição do experimento}

Os testes do SOS móvel desenvolvidos neste trabalho foram realizados em um ambiente aberto, com simulação de seis atividades, que são elas: Parado, caminhando, correndo, bicicleta, colisão e capotamento. Foram realizados vinte testes para cada atividade dessa citada, resultando em 120 resultados coletados.

Os critérios destacados nos testes para obtenção de resultados significativos foram as rotações, os eixos do acelerômetro, a atividade que foi detectada pela API Activity Recognition, a conclusão de ocorrência sob os dados recebidos, o tempo de envio de alerta e se houve sucesso ou não no resultado coletado. Cada critério descrito corresponde a uma coluna da tabela gerada.

No que diz respeito à rotação, para identificar sua ocorrência é utilizado o giroscópio com análise de seus dados à parte dos demais sensores. Isso foi necessário, pois torna-se irrelevante obter apenas um resultado em um dado momento sem analisar os dados anteriores. Então, para identificar o movimento de rotação, é armazenado aproximadamente 200 milissegundos de dados do giroscópio em um vetor e comparado o valor atual com outros n valores anteriores dentro de uma janela de tempo. Dessa forma, quando o valor obtido do eixo y tiver mudança de sinal em comparação com os valores anteriores, é indicada a rotação.

Os eixos do acelerômetro são obtidos de forma diferente do giroscópio devido a esse não necessitar de um histórico de variações, considerando que o acelerômetro está sendo usado para verificar as acelerações, torna-se 
relevante, apenas, obter o dado maior do que o padrão de normalidade encontrado de $5 \mathrm{~m} / \mathrm{s}^{2}$. Para obter esse padrão, foram realizados alguns pré-testes para obtenção de padrões de regularidade.

O critério de atividade detectada é de responsabilidade da API Activity Recognition, já o critério de conclusão obtida leva em consideração a análise da rotação, dos eixos do acelerômetro e da atividade detectada pelo usuário. Havendo rotação e valores excedentes para o acelerômetro, é identificada uma situação de risco, que se encaixa a atividade do usuário.

O tempo de envio de alerta é dado em segundos e diz respeito ao intervalo entre o momento de detecção da situação de risco e a de envio de alerta de confirmação para o Smartphone. Como forma de redução de erros dos alertas gerados, é exibida uma mensagem de confirmação da ocorrência. Se o usuário não anular o alerta em 1 minuto, é enviado um alerta aos familiares ou cuidadores e ao monitoramento web.

\subsection{Avaliação do experimento}

Nesta seção, serão apresentados os resultados obtidos pelos testes simulados para as 6 atividades identificadas com o SOS móvel.

\subsubsection{Caso 1: Parado}

Para a atividade "Parado", as simulações foram realizadas com o Smartphone na extremidade do braço humano a partir do pulso e simulando uma queda sob uma camada de ar obtida por compressão, sobre a qual foi apoiado o corpo em desaceleração. A Tabela 1 expõe os resultados dos testes realizados para a atividade em questão.

\begin{tabular}{|l|l|l|l|l|l|l|l|l|}
\hline \multicolumn{7}{|c|}{ Tabela 1: Dados obtidos estando sem movimento } \\
\hline $\mathbf{N}^{\mathbf{o}}$ & Rotação & Eixo X & Eixo Y & Eixo Z & $\begin{array}{l}\text { Atividade } \\
\text { detectada }\end{array}$ & Conclusão obtida & $\begin{array}{l}\text { Tempo de envio } \\
\text { de alerta }\end{array}$ & $\begin{array}{l}\text { Resultado } \\
\text { coletado }\end{array}$ \\
\hline 1 & Sim & 0,003 & 10,926 & 0,005 & Parado & Queda/Desmaio & 0,79 & Acerto \\
\hline 2 & Não & 6,865 & 0,055 & 0,028 & Parado & Queda/Desmaio & 0,89 & Acerto \\
\hline 3 & Não & 6,731 & 0 & 0,025 & Parado & Queda/Desmaio & 1,17 & Acerto \\
\hline 4 & Não & 6,655 & 0,013 & 0,076 & Parado & Queda/Desmaio & 1,07 & Acerto \\
\hline 5 & Sim & 0,059 & 11,254 & 0,064 & Parado & Queda/Desmaio & 0,61 & Acerto \\
\hline 6 & Não & 11,605 & 0,068 & 0,021 & Parado & Queda/Desmaio & 0,77 & Acerto \\
\hline 7 & Não & 0,043 & 0,008 & 11,201 & Parado & Queda/Desmaio & 0,56 & Acerto \\
\hline 8 & Não & 8,843 & 0,066 & 0,084 & Parado & Queda/Desmaio & 0,63 & Acerto \\
\hline 9 & Sim & 9,308 & 0,029 & 0,001 & Parado & Queda/Desmaio & 0,99 & Acerto \\
\hline 10 & Não & 0,02 & 6,747 & 0,084 & Parado & Queda/Desmaio & 1,11 & Acerto \\
\hline 11 & Não & 6,9 & 0,083 & 0,003 & Parado & Queda/Desmaio & 0,58 & Acerto \\
\hline 12 & Não & 0,094 & 8,704 & 0,001 & Parado & Queda/Desmaio & 0,99 & Acerto \\
\hline 13 & Não & 7,698 & 0,058 & 0,059 & Parado & Queda/Desmaio & 1,07 & Acerto \\
\hline 14 & Sim & 0,058 & 0,029 & 6,726 & Parado & Queda/Desmaio & 0,47 & Acerto \\
\hline 15 & Não & 0,096 & 7,34 & 0,067 & Parado & Queda/Desmaio & 1,18 & Acerto \\
\hline 16 & Sim & 8,648 & 0,019 & 0,026 & Parado & Queda/Desmaio & 1,16 & Acerto \\
\hline 17 & Sim & 8,086 & 0,028 & 0,002 & Parado & Queda/Desmaio & 1,29 & Acerto \\
\hline 18 & Sim & 7,817 & 0,075 & 0,074 & Parado & Queda/Desmaio & 0,48 & Acerto \\
\hline 19 & Não & 11,389 & 0,015 & 0,041 & Parado & Queda/Desmaio & 0,84 & Acerto \\
\hline 20 & Não & 10,911 & 0,083 & 0,09 & Parado & Queda/Desmaio & 0,62 & \\
\hline
\end{tabular}

Fonte: dados da pesquisa.

Durante a simulação para essa categoria, dos sete testes com rotação positiva, dois obtiveram rotação no acelerômetro no eixo y, ou seja, captada variação acima do limite do movimento na vertical do Smartphone. Ainda, quatro testes com variação no eixo x e apenas um no eixo z. Os quatorze demais testes, aqueles com 
rotação negativa, dez tiveram rotação no eixo $\mathrm{x}$ (movimento na horizontal), três no eixo y e um no eixo $\mathrm{z}$ (movimento para cima e para baixo).

Para cada teste realizado, foi gerado separadamente um gráfico que exibe os dados do giroscópio para o critério de rotação. Na Figura 5, são exibidos os dados referentes aos duzentos valores armazenados para o Teste 1 da Tabela 1. Pode-se perceber que houve mudança de sinal do eixo do giroscópio, caracterizando, assim, a presença de rotação no Smartphone. Vale salientar que todos os resultados nos quais foram identificados movimentos giratórios obtiveram dados com valores semelhantes de comportamento.

Figura 5: Gráfico de rotação para o teste 1 da atividade "parado"

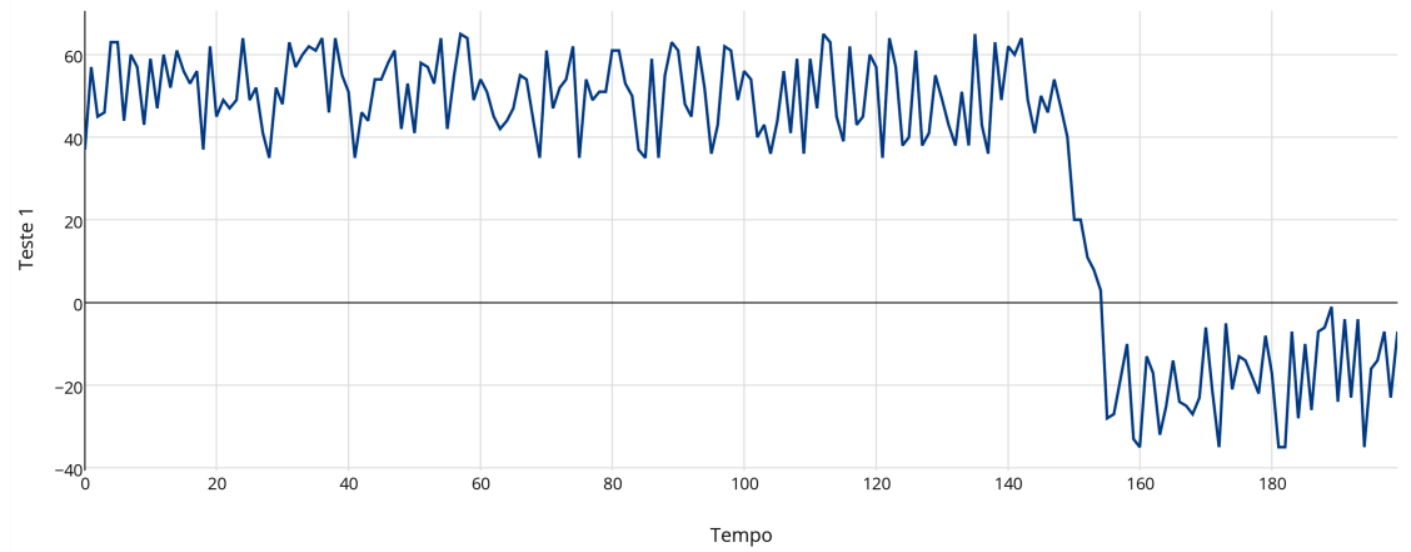

Fonte: dados da pesquisa

Para os casos em que não ocorreram rotação, os gráficos permanecem com os dados em um mesmo quadrante, ou seja, sem presença de variação de sinal. Nos testes coletados, há presença de valores aproximadamente entre -40 e 70 para o giroscópio nessa atividade, porém, não são valores fixos ou absolutos. A Figura 6 exibe as alterações do sensor para o Teste 20.

Figura 6: Gráfico de rotação para o teste 20 da atividade "parado"

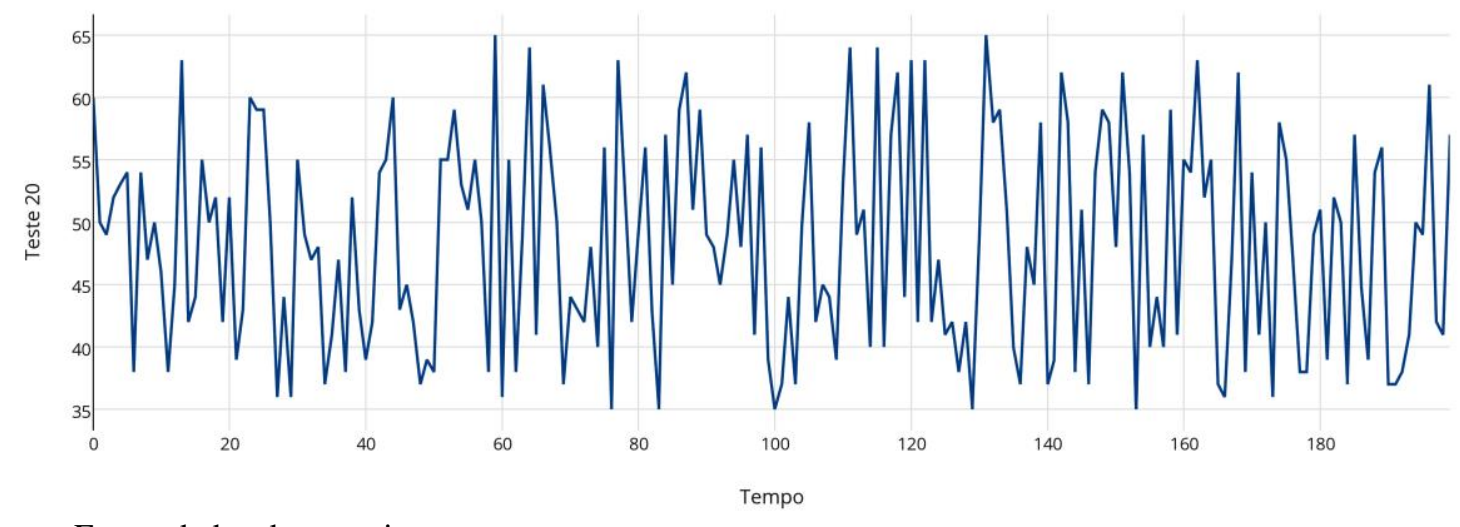

Fonte: dados da pesquisa

Fazendo uma comparação entre as duas Figuras apresentadas, pode-se perceber que para os dois casos, tanto o que houve rotação, quanto esse sem rotação, ambos não precisaram ter um valor fixo limite para identificação do movimento giratório, e, sim, uma análise do comportamento do sensor ao longo do tempo de uso. Para todos os testes, a API Activity Recognition identificou a atividade "parado", sendo eficiente e obtendo resultado satisfatório para os testes nessa categoria. A média de tempo para o envio dos alertas para essa atividade foi de 0,865 segundos.

\subsubsection{Caso 2: "caminhando"}

Assim como a atividade "parado", os testes para a atividade "caminhando" foram também realizados com o Smartphone na extremidade do braço humano, a partir do pulso, simulando uma caminhada simples 
seguida de uma diminuição da intensidade, declivando sob a superfície flexível usada para apoio do corpo em desaceleração. A Tabela 2 expõe os resultados dos testes realizados para a atividade em questão.

Em três testes a API Activity Recognition detectou equivocadamente atividades como "correndo" e "parado", porém esses casos em específico não afetaram a conclusão obtida, visto que mesmo não realizando as ações identificadas, identificação errônea nesse caso, considerando os dados de rotação e do acelerômetro, o usuário pode ter sofrido uma queda ou um desmaio e precisar de ajuda. Entretanto, em um caso em específico, não foi reconhecida nenhuma ação pela API, o que caracterizou um erro devido à não detecção da atividade e, consequentemente, ao impacto não identificado.

O resultado coletado obteve taxa de acerto satisfatória, salvo o teste em que não foi identificada a atividade. A média de tempo para o envio dos alertas para esta atividade foi de 0,775 segundos. Os Testes realizados para a atividade "Caminhando" estão representados na Tabela 2. A maioria dos testes obteve variação no eixo y do acelerômetro e grande parte com rotação.

Tabela 2: Dados obtidos no estado "caminhando"

\begin{tabular}{|r|l|r|r|r|l|l|l|l|}
\hline $\mathbf{N}^{\mathbf{n}}$ & Rotação & Eixo X & Eixo Y & Eixo Z & $\begin{array}{l}\text { Atividade } \\
\text { detectada }\end{array}$ & Conclusão obtida & $\begin{array}{l}\text { Tempo de envio } \\
\text { de alerta }\end{array}$ & $\begin{array}{l}\text { Resultado } \\
\text { coletado }\end{array}$ \\
\hline 1 & Sim & 0,003 & 10,926 & 0,005 & Parado & Queda/Desmaio & 0,79 & Acerto \\
\hline 2 & Não & 6,865 & 0,055 & 0,028 & Parado & Queda/Desmaio & 0,89 & Acerto \\
\hline 3 & Não & 6,731 & 0 & 0,025 & Parado & Queda/Desmaio & 1,17 & Acerto \\
\hline 4 & Não & 6,655 & 0,013 & 0,076 & Parado & Queda/Desmaio & 1,07 & Acerto \\
\hline 5 & Sim & 0,059 & 11,254 & 0,064 & Parado & Queda/Desmaio & 0,61 & Acerto \\
\hline 6 & Não & 11,605 & 0,068 & 0,021 & Parado & Queda/Desmaio & 0,77 & Acerto \\
\hline 7 & Não & 0,043 & 0,008 & 11,201 & Parado & Queda/Desmaio & 0,56 & Acerto \\
\hline 8 & Não & 8,843 & 0,066 & 0,084 & Parado & Queda/Desmaio & 0,63 & Acerto \\
\hline 9 & Sim & 9,308 & 0,029 & 0,001 & Parado & Queda/Desmaio & 0,99 & Acerto \\
\hline 10 & Não & 0,02 & 6,747 & 0,084 & Parado & Queda/Desmaio & 1,11 & Acerto \\
\hline 11 & Não & 6,9 & 0,083 & 0,003 & Parado & Queda/Desmaio & 0,58 & Acerto \\
\hline 12 & Não & 0,094 & 8,704 & 0,001 & Parado & Queda/Desmaio & 0,99 & Acerto \\
\hline 13 & Não & 7,698 & 0,058 & 0,059 & Parado & Queda/Desmaio & 1,07 & Acerto \\
\hline 14 & Sim & 0,058 & 0,029 & 6,726 & Parado & Queda/Desmaio & 0,47 & Acerto \\
\hline 15 & Não & 0,096 & 7,34 & 0,067 & Parado & Queda/Desmaio & 1,18 & Acerto \\
\hline 16 & Sim & 8,648 & 0,019 & 0,026 & Parado & Queda/Desmaio & 1,16 & Acerto \\
\hline 17 & Sim & 8,086 & 0,028 & 0,002 & Parado & Queda/Desmaio & 1,29 & Acerto \\
\hline 18 & Sim & 7,817 & 0,075 & 0,074 & Parado & Queda/Desmaio & 0,48 & Acerto \\
\hline 19 & Não & 11,389 & 0,015 & 0,041 & Parado & Queda/Desmaio & 0,84 & Acerto \\
\hline 20 & Não & 10,911 & 0,083 & 0,09 & Parado & Queda/Desmaio & 0,62 & Acerto \\
\hline & & & & & & & & \\
\hline
\end{tabular}

Fonte: dados da pesquisa

\subsubsection{Caso 3: "correndo"}

As simulações realizadas para a atividade "correndo" assemelham-se às demais, uma vez que não é necessário ter meios de deslocamento além da própria movimentação humana para realização dos testes. A Tabela 3 expõe os resultados dos testes realizados para a atividade em questão.

Tabela 3: dados obtidos no estado "correndo"

\begin{tabular}{|c|c|c|c|c|c|c|c|c|}
\hline $\mathbf{N}^{\mathbf{o}}$ & Rotação & Eixo X & Eixo $Y$ & Eixo $Z$ & $\begin{array}{l}\text { Atividade } \\
\text { detectada }\end{array}$ & $\begin{array}{l}\text { Conclusão } \\
\text { obtida }\end{array}$ & $\begin{array}{l}\text { Tempo de envio } \\
\text { de alerta }\end{array}$ & $\begin{array}{l}\text { Resultado } \\
\text { coletado }\end{array}$ \\
\hline 1 & Sim & 0,363 & 11,294 & 0,171 & Correndo & Queda & 0,5 & Acerto \\
\hline
\end{tabular}




\begin{tabular}{|r|l|r|r|r|l|l|r|l|}
2 & Sim & 0,295 & 0,164 & 10,812 & Correndo & Queda & 0,42 & Acerto \\
\hline 3 & Sim & 10,25 & 0,271 & 7,512 & Caminhando & Queda & 1,43 & Acerto \\
\hline 4 & Não & 0,239 & 0,244 & 9,303 & Correndo & Queda & 1,01 & Acerto \\
\hline 5 & Não & 0,451 & 9,479 & 0,114 & Correndo & Queda & 0,63 & Acerto \\
\hline 6 & Sim & 0,274 & 0,191 & 11,573 & Correndo & Queda & 0,53 & Acerto \\
\hline 7 & Sim & 7,463 & 0,143 & 0,185 & Correndo & Queda & 1,37 & Acerto \\
\hline 8 & Sim & 0,12 & 0,324 & 9,489 & Correndo & Queda & 1,1 & Acerto \\
\hline 9 & Sim & 7,98 & 0,128 & 9,685 & Correndo & Queda & 0,72 & Acerto \\
\hline 10 & Sim & 0,188 & 11,519 & 0,28 & Caminhando & Queda & 1,13 & Acerto \\
\hline 11 & Sim & 11,45 & 14,22 & 10,402 & Parado & Queda & 1,12 & Acerto \\
\hline 12 & Sim & 0,47 & 7,967 & 0,246 & Correndo & Queda & 1,33 & Acerto \\
\hline 13 & Não & 0,171 & 0,292 & 10,674 & Correndo & Queda & 1,37 & Acerto \\
\hline 14 & Sim & 10,539 & 0,231 & 0,28 & Correndo & Queda & 0,58 & Acerto \\
\hline 15 & Sim & 8,49 & 11,519 & 0,22 & Caminhando & Queda & 1,03 & Acerto \\
\hline 16 & Sim & 0,158 & 0,166 & 7,688 & Correndo & Queda & 1,04 & Acerto \\
\hline 17 & Sim & 0,24 & 10,34 & 8,967 & Correndo & Queda & 0,68 & Acerto \\
\hline 18 & Não & 7,44 & 0,103 & 9,866 & Correndo & Queda & 1,31 & Acerto \\
\hline 19 & Sim & 0,256 & 0,252 & 7,45 & Correndo & Queda & 1,36 & Acerto \\
\hline 20 & Sim & 11,63 & 0,272 & 8,59 & Correndo & Queda & 0,42 & Acerto \\
\hline
\end{tabular}

Fonte: dados da pesquisa

Para a atividade em questão, não houve erros detectados, uma vez que a API conseguiu identificar as atividades corretamente na maioria dos casos, exceto em quatro testes, alternando os resultados entre "caminhando" e "parado". Dos vinte testes, dezesseis foram realizados com rotação no Smartphone.

O tempo médio de envio de alerta para essa atividade foi de 1,035 segundos e o teste com maior espera foi um dos que não foram detectados corretamente pela API. Não houve nenhum erro no resultado coletado e na conclusão obtida pelo SOS Móvel, apesar da API não ter identificado todas as ações corretamente. O desempenho testado para essa atividade foi considerado satisfatório, sem evidência de erros.

\subsubsection{Caso 4: "bicicleta"}

Para a atividade "bicicleta", os testes foram realizados utilizando o meio de transporte em questão e em baixa velocidade, simulando um impacto seguido de apoio do dispositivo móvel sob uma região do corpo. O resultado dos testes pode ser visualizado na Tabela 4.

Tabela 4: Dados obtidos da "bicicleta"

\begin{tabular}{|r|l|r|r|r|l|l|l|l|}
\hline $\mathbf{N}^{\mathbf{o}}$ & Rotação & $\begin{array}{l}\text { Eixo } \\
\text { X }\end{array}$ & Eixo Y & Eixo Z & $\begin{array}{l}\text { Atividade } \\
\text { detectada }\end{array}$ & Conclusão obtida & $\begin{array}{l}\text { Tempo de envio } \\
\text { de alerta }\end{array}$ & $\begin{array}{l}\text { Resultado } \\
\text { coletado }\end{array}$ \\
\hline 1 & Sim & 0,752 & 7,594 & 0,252 & Bicicleta & Queda de bicicleta & 1,05 & Acerto \\
\hline 2 & Sim & 7,45 & 0,215 & 0,22 & Bicicleta & Queda de bicicleta & 0,79 & Acerto \\
\hline 3 & Sim & 0,269 & 0,515 & 11,866 & Bicicleta & Queda de bicicleta & 1,09 & Acerto \\
\hline & & & & & $\begin{array}{l}\text { Atividade } \\
\text { não } \\
\text { identificada }\end{array}$ & $\begin{array}{l}\text { Impacto não } \\
\text { identificado }\end{array}$ & 0,44 & Erro \\
\hline 4 & Sim & 11,36 & 0,314 & 8,23 & 0,54 & Acerto \\
\hline 5 & Não & 0,424 & 7,407 & 0,576 & Bicicleta & Queda de bicicleta & 0,52 & Acerto \\
\hline 6 & Sim & 0,354 & 0,645 & 7,351 & Bicicleta & Queda de bicicleta & & \\
\hline 7 & Sim & 8,226 & 0,2 & 0,423 & Carro & $\begin{array}{l}\text { Capotamento do } \\
\text { carro }\end{array}$ & 0,47 & Erro \\
\hline 8 & Sim & 0,224 & 0,419 & 8,325 & Bicicleta & Queda de bicicleta & 0,53 & Acerto \\
\hline
\end{tabular}




\begin{tabular}{|r|l|r|r|r|l|l|r|l|}
9 & Sim & 13,86 & 0,279 & 11,943 & Correndo & Queda de bicicleta & 1,19 & Acerto \\
\hline 10 & Sim & 0,212 & 10,427 & 0,258 & Bicicleta & Queda de bicicleta & 0,8 & Acerto \\
\hline 11 & Sim & 13,41 & 0,265 & 10,512 & Bicicleta & Queda de bicicleta & 0,73 & Acerto \\
\hline 12 & Sim & 0,666 & 6,748 & 0,695 & Carro & $\begin{array}{l}\text { Capotamento do } \\
\text { carro }\end{array}$ & 0,88 & Erro \\
\hline 13 & Sim & 0,183 & 0,704 & 7,011 & Bicicleta & Queda de bicicleta & 0,83 & Acerto \\
\hline 14 & Sim & 8,86 & 0,678 & 0,23 & Bicicleta & Queda de bicicleta & 0,83 & Acerto \\
\hline 15 & Sim & 0,172 & 7,419 & 0,682 & Bicicleta & Queda de bicicleta & 1,47 & Acerto \\
\hline 16 & Sim & 0,662 & 0,272 & 11,624 & Bicicleta & Queda de bicicleta & 1,43 & Acerto \\
\hline 17 & Não & 0,598 & 0,768 & 10,503 & Bicicleta & Queda de bicicleta & 0,93 & Acerto \\
\hline 18 & Não & 0,625 & 0,552 & 7,569 & Carro & Batida de carro & 1,49 & Erro \\
\hline 19 & Sim & 12,29 & 0,147 & 0,22 & Bicicleta & Queda de bicicleta & 1,07 & Acerto \\
\hline 20 & Sim & 0,75 & 0,452 & 7,347 & Bicicleta & Queda de bicicleta & 1,2 & Acerto \\
\hline
\end{tabular}

Fonte: dados da pesquisa

Como foi utilizado um meio externo para os testes, os valores para o acelerômetro tiveram números mais elevados e, consequentemente, acima dos limites estabelecidos para normalidade. Entretanto, foram captados apenas quatro erros referentes à não identificação da atividade e ao reconhecimento errado da ação do usuário, ambos por parte da interpretação e funcionamento da API.

Para os testes sete e doze, nos quais foi detectada a atividade "carro" ao invés de "bicicleta", a variação no acelerômetro foi apresentada em apenas um dos eixos, tendo pouca atividade nos demais eixos. O teste sete foi simulado com rotação e o valor significativo para o acelerômetro foi de $8,23 \mathrm{~m} / \mathrm{s}^{2}$ obtido apenas no eixo x. Já o teste doze, também com movimento rotatório, obteve $6,75 \mathrm{~m} / \mathrm{s}^{2}$ de variação máxima apenas no eixo y. A identificação da ocorrência fora da normalidade, nesse caso, foi correta. Porém, a conclusão para situação envolvida foi errada.

\subsubsection{Caso 5: "carro"}

Os acidentes de transporte resultam em 26,2\% de acidentes mais frequentes no país. Dessa forma, decidiu-se utilizar a identificação de situações de risco para duas vertentes principais ligadas ao ambiente veicular: colisão e capotamento. A primeira delas diz respeito ao impacto frontal entre dois automóveis, enquanto que o capotamento se trata de dar a volta sobre seu próprio eixo uma ou mais vezes. Os testes para essa atividade foram realizados em um ambiente automotivo com simulações que se aproximaram da ação.

\subsubsection{Caso 6: "colisão"}

Para captação dos testes, o veículo encontrava-se em movimento e era impulsionado o Smartphone para frente na horizontal, similar a um impacto sem rotação de uma colisão frontal real. A frenagem foi simulada, amortecendo o Smartphone nas mãos para desaceleração rápida. Vale salientar que, para essa atividade específica, houve certa cautela para realização das simulações, pois para sucesso dos testes não deveria haver rotação no Smartphone, visto que é simulada uma colisão frontal sem movimentos giratórios.

A Tabela 5 mostra os resultados obtidos para a atividade "carro" com a ocorrência de uma colisão. Como se pode observar, foram obtidos dezesseis resultados assertivos e apenas quatro erros. Nos testes 7 e 10, a API identificou corretamente a atividade do usuário, porém, a aplicação falhou ao não distinguir corretamente a colisão do capotamento. $\mathrm{O}$ erro se deu ao fato de o giroscópio ter identificado movimento rotatório quando na verdade teria sido apenas uma frenagem.

Tabela 5: Dados obtidos para "colisão"

\begin{tabular}{|r|l|r|r|r|l|l|l|l|}
\hline $\mathbf{N}^{\mathbf{0}}$ & Rotação & Eixo X & Eixo Y & Eixo Z & $\begin{array}{l}\text { Atividade } \\
\text { detectada }\end{array}$ & Conclusão obtida & $\begin{array}{l}\text { Tempo de envio } \\
\text { de alerta }\end{array}$ & $\begin{array}{l}\text { Resultado } \\
\text { coletado }\end{array}$ \\
\hline 1 & Não & 15,22 & 12,645 & 0,208 & Carro & Batida de carro & 1,36 & Acerto \\
\hline 2 & Não & 1,581 & 14,075 & 14,035 & Carro & Batida de carro & 1,06 & Acerto \\
\hline 3 & Não & 14,472 & 1,284 & 11,986 & Carro & Batida de carro & 0,53 & Acerto \\
\hline 4 & Não & 1,186 & 0,784 & 14,887 & Carro & Batida de carro & 0,78 & Acerto \\
\hline
\end{tabular}




\begin{tabular}{|c|c|c|c|c|c|c|c|c|}
\hline 5 & Não & 0,674 & 11,671 & 0,627 & Carro & Batida de carro & 0,49 & Acerto \\
\hline 6 & Não & 0,607 & 1,46 & 13,107 & Carro & Batida de carro & 0,76 & Acerto \\
\hline 7 & Sim & 6,571 & 14,313 & 0,815 & Carro & $\begin{array}{l}\text { Capotamento do } \\
\text { carro }\end{array}$ & 1,41 & Erro \\
\hline 8 & Não & 1,729 & 13,948 & 10,413 & Carro & Batida de carro & 1,33 & Acerto \\
\hline 9 & Não & 1,424 & 1,058 & 10,491 & Carro & Batida de carro & 0,51 & Acerto \\
\hline 10 & Sim & 0,29 & 11,254 & 11,14 & Carro & $\begin{array}{l}\text { Capotamento do } \\
\text { carro }\end{array}$ & 0,98 & Erro \\
\hline 11 & Não & 1,146 & 1,499 & 7,704 & Carro & Batida de carro & 1,42 & Acerto \\
\hline 12 & Não & 0,68 & 12,833 & 9,36 & Correndo & Queda & 0,58 & Erro \\
\hline 13 & Não & 6,557 & 1,236 & 6,6 & Carro & Batida de carro & 0,9 & Acerto \\
\hline 14 & Não & 12,669 & 0,601 & 0,174 & Carro & Batida de carro & 1,27 & Acerto \\
\hline 15 & Não & 1,495 & 12,524 & 1,078 & Carro & Batida de carro & 0,58 & Acerto \\
\hline 16 & Sim & 14,25 & 0,81 & 14,932 & Correndo & Queda & 0,67 & Erro \\
\hline 17 & Não & 1,09 & 1,028 & 10,417 & Carro & Batida de carro & 0,54 & Acerto \\
\hline 18 & Não & 11,29 & 1,712 & 13,048 & Carro & Batida de carro & 0,95 & Acerto \\
\hline 19 & Não & 1,015 & 12,009 & 14,684 & Carro & Batida de carro & 0,56 & Acerto \\
\hline 20 & Não & 12,94 & 1,008 & 10,152 & Carro & Batida de carro & 1,42 & Acerto \\
\hline
\end{tabular}

Fonte: dados da pesquisa

As simulações para essa atividade apresentaram equívocos da API em dois casos em que foi captada uma atividade diferente da executada nos testes. Tal imprecisão resultou em dois erros fatais. Os demais erros foram decorrentes da identificação errada da rotação no dispositivo móvel. O tempo médio de envio de alertas para essa atividade foi de 0,84 segundos. O desempenho para essa atividade foi considerado satisfatório mediante a quantidade de acertos obtidos em virtude dos erros existentes

\subsubsection{Caso 7: "capotamento"}

A captação dos testes para capotamento também se deu com o veículo em movimento e com o dispositivo móvel posicionado nas mãos. A simulação se deu com o impulsionamento do Smartphone para frente com rotação. A frenagem também foi simulada, fazendo o dispositivo móvel perder a intensidade da ação nas mãos.

O resultado dos testes pode ser visualizado na Tabela 6. Para a atividade de identificação de capotamento, os resultados constataram uma ocorrência maior de erros em relação às demais atividades, resultando em cinco erros e quinze acertos. Com a simulação, pode-se notar que, em apenas um caso, houve identificação equivocada da rotação do dispositivo móvel, o que ocasionou o erro do resultado coletado. Outro erro identificado foi na detecção da atividade do usuário, onde a API falhou 4 vezes por classificar erroneamente estas ações.

Nos testes 1 e 19, o acelerômetro obteve valores acima do normal estabelecido nos três eixos simultaneamente, caracterizando um movimento de volta sobre seu próprio eixo. Os demais testes obtiveram variação, na maioria dos casos, em dois eixos ou em apenas um. A média de tempo para envio de alertas para essa atividade foi de 0,72 segundos.

Tabela 6: Dados obtidos para o caso de capotamento

\begin{tabular}{|r|l|r|r|r|l|l|r|l|}
\hline $\mathbf{N}^{\mathbf{o}}$ & Rotação & Eixo X & Eixo Y & Eixo Z & $\begin{array}{l}\text { Atividade } \\
\text { detectada }\end{array}$ & Conclusão obtida & $\begin{array}{l}\text { Tempo de } \\
\text { envio de alerta }\end{array}$ & $\begin{array}{l}\text { Resultado } \\
\text { coletado }\end{array}$ \\
\hline 1 & Sim & 16,33 & 12,656 & 10,29 & Carro & Capotamento do carro & 0,83 & Acerto \\
\hline 2 & Sim & 0,757 & 8,236 & 14,553 & Carro & Capotamento do carro & 1,02 & Acerto \\
\hline 3 & Não & 14,043 & 0,653 & 8,284 & Carro & Batida do carro & 0,61 & Acerto \\
\hline 4 & Sim & 1,207 & 1,188 & 14,441 & Correndo & Queda & 1,16 & Erro \\
\hline 5 & Sim & 1,196 & 7,408 & 1,341 & Carro & Capotamento do carro & 0,78 & Acerto \\
\hline 6 & Sim & 0,738 & 1,168 & 12,187 & Carro & Capotamento do carro & 0,71 & Acerto \\
\hline
\end{tabular}




\begin{tabular}{|c|c|c|c|c|c|c|c|c|}
\hline 7 & Sim & 9,609 & 13,61 & 1,457 & Carro & Capotamento do carro & 0,53 & Acerto \\
\hline 8 & Sim & 1,546 & 12,936 & 13,193 & Carro & Capotamento do carro & 1,36 & Acerto \\
\hline 9 & Sim & 15,27 & 1,212 & 2,65 & Carro & Capotamento do carro & 0,73 & Acerto \\
\hline 10 & Sim & 0,215 & 13,856 & 0,295 & $\begin{array}{l}\text { Atividade } \\
\text { não } \\
\text { identificada }\end{array}$ & $\begin{array}{l}\text { Impacto não } \\
\text { identificado }\end{array}$ & 0,55 & Erro \\
\hline 11 & Sim & 16,29 & 0,678 & 0,26 & Carro & Capotamento do carro & 0,78 & Acerto \\
\hline 12 & Não & 1,092 & 11,422 & 0,711 & Carro & Batida do carro & 0,5 & Erro \\
\hline 13 & Sim & 6,56 & 0,753 & 14,611 & Carro & Capotamento do carro & 0,51 & Acerto \\
\hline 14 & Sim & 14,546 & 1,581 & 0,201 & Carro & Capotamento do carro & 0,93 & Acerto \\
\hline 15 & Sim & 1,46 & 8,701 & 0,591 & Bicicleta & Queda de bicicleta & 0,46 & Erro \\
\hline 16 & Sim & 1,768 & 1,166 & 9,527 & Carro & Capotamento do carro & 1,11 & Acerto \\
\hline 17 & Sim & 10,5 & 1,168 & 7,118 & Bicicleta & Queda de bicicleta & 0,56 & Erro \\
\hline 18 & Sim & 0,772 & 10,88 & 8,991 & Carro & Capotamento do carro & 0,58 & Acerto \\
\hline 19 & Sim & 10,85 & 11,295 & 13,067 & Carro & Capotamento do carro & 1,36 & Acerto \\
\hline 20 & Sim & 11,35 & 0,56 & 13,828 & Carro & Capotamento do carro & 0,41 & Acerto \\
\hline
\end{tabular}

\subsection{Discussões e resultados}

Com base nos testes simulados, foi possível concluir que o SOS móvel obteve bom desempenho para as funções das quais foi encarregado, tendo sido simulados seis casos de utilização do sistema para identificação de situações de risco. Para cada caso isolado foram realizados vinte testes, resultando no total de 120 testes para a detecção e a tomada de decisão automática. A taxa geral de acertos obtida foi de $88,3 \%$, porém, analisando separadamente cada atividade, a "parado" obteve $100 \%$ de acertos, "caminhando" atingiu $95 \%$ de sucesso, "correndo" resultou também em 100\% de acerto, "bicicleta" e "colisão" obtiveram 80\% e "capotamento" resultou $75 \%$ de acertos, como apresentado na Figura 7.

Figura 7: Gráficos de porcentagem de erros e acertos para cada atividade

PARADO

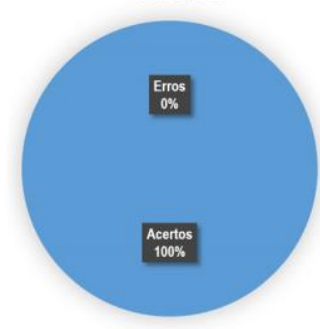

BICICLETA

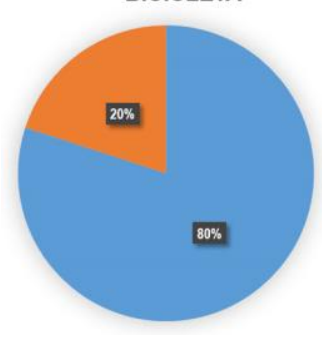

Fonte: dados da pesquisa
CAMINHANDO
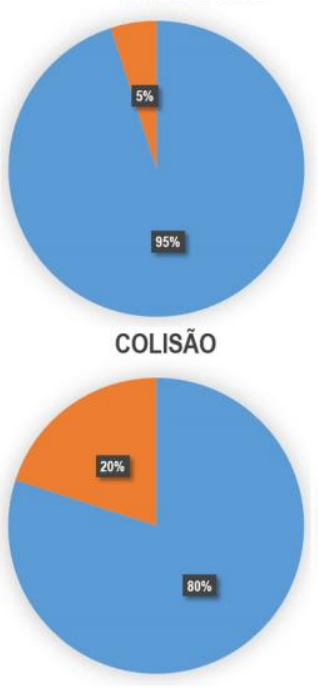

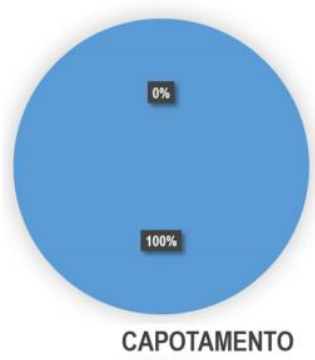

CORRENDO

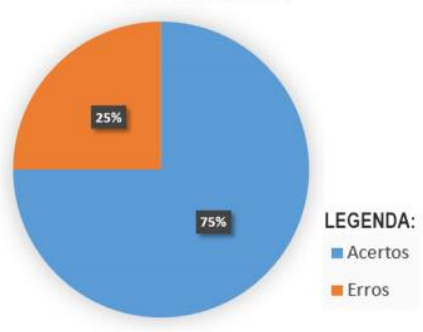


Das seis atividades captadas e simuladas, as que obtiveram $100 \%$ de aproveitamento e acerto nos testes foram a de "parado" e de "correndo". As demais obtiveram pelo menos um erro em um dos testes. A atividade "caminhando" teve apenas um erro e as atividades "bicicleta" e "colisão" tiveram quatro erros cada. As simulações que obtiveram maior erros foram as de "Capotagem", com cinco erros. A API teve 84,2\% de acertos de identificação da atividade, resultando em 101 atividades captadas corretamente; e de 15,8\% para identificação errada ou ausente da atividade.

\section{Considerações finais}

Os diversos testes realizados permitiram concluir que o sistema apresentou desempenho conforme especificado e é adequado para o monitoramento remoto de atividades de autocuidados em usuários com alguma doença crítica, com potencial para aplicação em diversos casos. Pode-se salientar, também, que, por conta de o modelo proposto atender as necessidades primárias de envio e recebimento de alertas emergenciais, esse pode ser utilizado por uma unidade médica de atendimento para auxílio a população.

O SOS móvel foi desenvolvido para Smartphones com o sistema operacional Android que possuam a versão 4.0.3 (Ice Cream Sandwich) ou versões superiores. Fundamentando-se nessa premissa, como limitações para o uso do SOS móvel, tem-se que a instalação é possível apenas em dispositivos Android. Além disso, é necessária a conexão com a internet para envio e recebimento de alertas.

O SOS Web para uso dos profissionais da saúde, cuidadores ou familiares foi desenvolvido baseado em plataformas web, funcionando, assim, em qualquer navegador de qualquer dispositivo com acesso à internet, excluindo portanto outras limitações. A utilização do SOS móvel e web possibilita rapidez e facilidade para informar acidentes ou situações de risco a familiares ou cuidadores. Também auxilia no processo de identificação da situação em que o usuário se encontra e o seu monitoramento.

A partir deste trabalho, surgem possibilidades de trabalhos futuros, como:

- A adição de identificação de novas atividades, e, consequentemente situações de risco aliadas a essas;

- Implantação do SOS móvel e web a um sistema de monitoramento de serviço de urgência e atendimento médico de ambiente real;

- Agregar a utilização de mais sensores ao sistema para maior precisão dos dados obtidos;

- Melhorar e testar outras técnicas inteligentes e de correlações de dados;

- Desenvolver técnicas inteligentes para identificação e adaptação da rotina do usuário sem necessidade de intervenção desse.

\section{Agradecimentos}

Agradecemos ao Grupo de Engenharia de Software (GES) da Universidade do Estado do Rio Grande do Norte e a Capes.

\section{Referências}

[1] SECRETARIA DE VIGILÂNCIA EM SAÚDE. Viva: Vigilância de violências e acidentes: Sistema de vigilância de violências e acidentes. 1 ed. [S.1.]: Ministério da Saúde, 2013.

[2] CUNHA, A. Cavalo Do Século: Por Que Os Acidentes de Transito Acontecem? [S.1.]: Arte e Ciência, 2008.

[3] MÖLlER, E. d. S. Pervasividade no Contexto dos Dispositivos de Borda. [S.1]: Universidade Católica de Pelotas, 2006.

[4] DUARTE, F. J. A. Classificação de atividades físicas através do uso do acelerómetro do smartphone. [S.l.: S.n.], 2013.

[5] GOODRICH, R. Accelerometer vs. gyroscope: What's the difference? LiveScience Contributor, 2015. 
[6] SILVA, L. C.; NETO, F. M. M.; JÚNIOR, L. J. Mobile: Um ambiente multiagente de aprendizagem móvel baseado em algoritmo genético para apoiar a aprendizagem ubíqua. Revista Brasileira de Informática na Educação, v. 21, n. 01, p. 62, 2013.

[7] MAGAlHÃES, D. A. Vocalizador Digital Baseado na Computação Sensível ao Contexto. Dissertação (Mestrado) - Universidade do Estado do Rio Grande do Norte / Universidade Federal Rural do SemiÁrido, 2015.

[8] SHEPHERD, E.; PATONNIER, J.; YOSHINO, K. Orientation and motion data explained. 2014.

[9] RAZ, D.; JUHOLA, A. T.; SERRAT-FERNANDEZ, J.; GALIS, A. Fast and eficiente context-aware services. [S.1.]: John Wiley\& Sons, 2006.

[10] BLAYA, A.; JOAQUIN FRASER, S.; FERNANDES HOLT, B.; BRIAN. E-health technologies show promise in developing countries. [S.1.]: Health Affairs, 2010.

[11] GOMES, A.; GUANAES MORAES, J. B. M.; XAVIER TIMERMAN, S.; SERGIO. Telemedicina e sua aplicação em emergências. 2011. 